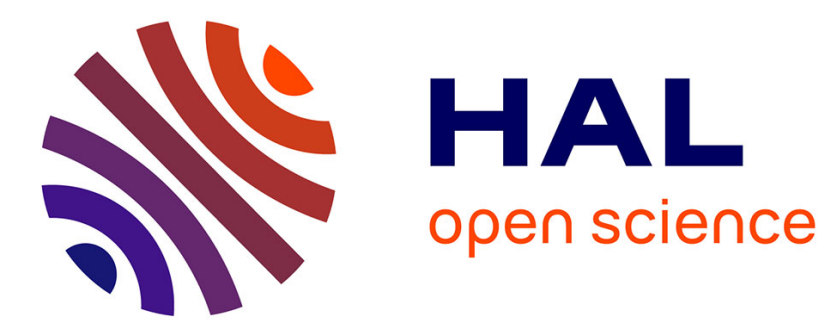

\title{
Automated Screw-pin adjustment for reconfigurable moulding machine
}

Yan Wang, Zhijian Wang, N N Z Gindy, Renzhong Tang, Xinjian Gu

\section{To cite this version:}

Yan Wang, Zhijian Wang, N N Z Gindy, Renzhong Tang, Xinjian Gu. Automated Screw-pin adjustment for reconfigurable moulding machine. International Journal of Computer Integrated Manufacturing, 2010, 23 (03), pp.229-236. 10.1080/09511920903527853 . hal-00567236

\section{HAL Id: hal-00567236 \\ https://hal.science/hal-00567236}

Submitted on 19 Feb 2011

HAL is a multi-disciplinary open access archive for the deposit and dissemination of scientific research documents, whether they are published or not. The documents may come from teaching and research institutions in France or abroad, or from public or private research centers.
L'archive ouverte pluridisciplinaire HAL, est destinée au dépôt et à la diffusion de documents scientifiques de niveau recherche, publiés ou non, émanant des établissements d'enseignement et de recherche français ou étrangers, des laboratoires publics ou privés. 


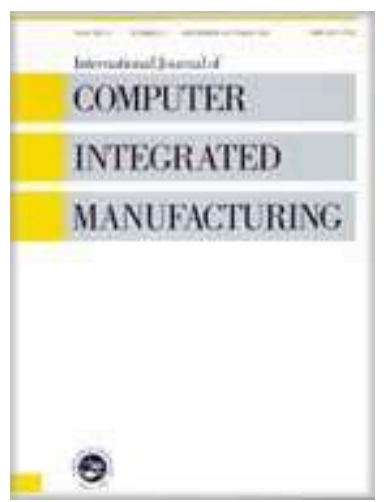

\section{Automated Screw-pin adjustment for reconfigurable moulding machine}

\begin{tabular}{|r|l|}
\hline Journal: & International Journal of Computer Integrated Manufacturing \\
\hline Manuscript ID: & TCIM-2009-IJCIM-0046.R1 \\
\hline Manuscript Type: & Original Manuscript \\
\hline Author: & 27-Oct-2009 \\
\hline & $\begin{array}{l}\text { Complete List of Authors: } \\
\text { Materials and Manufacturing Engineering } \\
\text { Materian N Z; The University of Nottingham, School of Mech, } \\
\text { Materials \&an Eng'g } \\
\text { Tang, Renzhong; Zhejiang University, College of Mechanic and } \\
\text { energy engineering } \\
\text { Gu, Xinjian; Zhejiang University, College of Mechanic and energy } \\
\text { engineering }\end{array}$ \\
\hline Keywords: & CAD/CAM, MOULD DESIGN, SOFTWARE ENGINEERING \\
\hline Keywords (user): & screw pin tooling, , reconfigurable moulding \\
\hline
\end{tabular}

\section{S ScholarONE" \\ Manuscript Central}




\section{Automated Discrete-pin adjustment for reconfigurable moulding machine}

\section{Abstract}

To stay competitive, the moulding industry must possess manufacturing systems that are responsive to rapid market changes. Reconfigurable moulding is therefore much in demand. After the development of a vacuum forming machine, in which the pins are configured to a near-net shape and machined to final shape with minimal material removal, this paper discusses in detail the support software development that enables the automatic adjustment of discrete-pins to represent different component geometry. In this paper, the methodology is firstly explained, and the implementation of the system within the software is then demonstrated. The software system includes three parts: (1) component discretization, (2) Discrete-pin construction, adjustment, and G code generation (SCAG) and (3) Display and verification. Vacuum forming of a car model is used as case study.

Key words: discrete pin tooling, reconfigurable moulding, automated pin adjustment

\section{Nomenclature}
$\boldsymbol{A}_{i j}$
The adjustment of the $(\mathrm{i}, \mathrm{j})^{\text {th }}$ discrete pin in degree
$C_{p}$ The number of column of the discrete-pin matrix
$D_{p}$ The nominal diameter of the discrete pin
$L_{p}$ Length of the discrete pin and pitch $\left(\mathbf{P}_{\mathbf{p}}\right)$.
$\mathbf{N}_{\mathbf{k}}^{\mathrm{ij}}(x, y, z)$ The $k^{\text {th }}$ node within the patch $S^{i j}, k \in[1, t]$
$\boldsymbol{P}_{i j}(x, y, z)$ The pin in the $\mathrm{i}^{\text {th }}$ row and $\mathrm{j}^{\text {th }}$ column of the discrete-pin matrix
The pitch of the discrete pin
$\boldsymbol{R}_{p}$ The number of row of the discrete-in matrix
$\mathbf{S}_{\mathrm{c}}$ $\mathrm{S}^{\mathrm{ij}}(x, y, z)$ A general 3D component surface $\mathbf{S}_{\mathbf{c}}$ $S_{t}$ The $(\mathrm{i}, \mathrm{j})^{\text {th }}$ NURBS patch of the $\mathbf{S}_{\mathbf{c}}$ in response to the $\mathbf{P}_{\mathrm{ij}}$ $X_{p}$ The tooling space constructed by the discrete-pin matrix Distance between the central axes of the two discrete pins next to each other in the $\mathrm{X}$ direction 
Distance between the central axes of the two discrete pins next to each other in the $Y$ direction

\section{Introduction}

Manufacturing companies in the 21st Century face unpredictable market changes. These changes include the frequent introduction of new products, changing product demand and mix, the manufacture of legacy parts for existing products, new government regulations, and new material and process technology. To stay competitive, manufacturing companies must possess manufacturing systems that are responsive to all these variables.

The moulding industry is a fundamental industry in many countries and moulding itself is regarded as one of the most important manufacturing processes. Currently, moulding machines are overwhelmingly dedicated, expensive and time-consuming and have become the bottle neck of the industry. Reconfigurable moulding is now much in demand as the moulding industry has to become more responsive to unpredictable market changes.

A new reconfigurable moulding machine utilising discrete-pin tooling is therefore proposed. The reconfigurable tooling of such machine is composed of an array of identical discrete-pins which are engaged with each other within a frame. By adjusting the vertical displacement of the discrete pins, a wider variety of component geometry can be formed, thus active control over the tool shape for the use with different components becomes possible.

Having developed a machine for reconfigurable moulding, the paper focuses on the software programme that enables automatic $G$ code generation for discrete pin adjustment that in turn enables its reconfigurability for different components.

\section{Prior art}

As defined by (Munro and Walczyk 2007), a reconfigurable tool herein is defined as a machine that can be repeatedly configured by a user to shape 
different mechanical parts in a manufacturing setting. Although most machines are reconfigurable by virtue of their replaceable cutting bits, dies, moulds, rollers, and the like, the machines discussed in this paper are reconfigurable pin-type tools with a variable surface similar to the popular three dimensional pin art or PinPressions ${ }^{\text {TM }}$ toy (Fleming 1987). Reconfigurable pin tools are often used for machining, forming, moulding or casting of complex curvature parts from metal, polymers, ceramics, wood and laminated composites from metal, polymers, ceramics, wood and laminated composites. Generally, reconfigurable pin tooling includes: reconfigurable work holding and reconfigurable moulding. Reconfigurable tooling is both economical and ecologically advantageous for the industry as one reconfigurable device serves many components, significantly reducing tooling costs and lead time in the manufacture of new components. Waste of material is also reduced both in the manufacturing process and in the disposal of workholding devices that are no longer needed.

Reconfigurable work holdings normally utilise an array of pins, which are pushed into contact with components and gently conformed to the component surface and lock into position. The support pins can be used to reduce machining deformation and vibration. In terms of the driving mechanism for work holding devices, two possibilities are spring advancing/mechanical locking (MATRIX GmbH Stuttgart) and pneumatic advancing/hydraulic locking (KOSTYRKA GmbH). Another approach to conformable fixtures has been the encapsulation of at least part of the component in phase changing materials, e.g. a low melting alloy containing lead (Camp 1978) or magnetorheological fluids (Rong et al 2000).

In terms of reconfigurable moulding, having reviewed the history of reconfigurable tooling patents from 1863 to 2003 and related research from the late 1960s to the present, Munro and Walczyk (2007) have suggested that although small-scale reconfigurable pin tool prototypes have been built for research and for one-off manufacturing projects, only limited designs have actually led to commercialisation. Two examples of the commercialisation of reconfigurable moulding machines are the multi-point forming system (MPF) and Reconfigurable Pin Tooling technology (Surface Generation). 
Multi-point forming (MPF) is a flexible forming method for sheet metal parts developed by a research group led by Prof. Li at Jilin University, China. It uses two reconfigurable pin groups which function as the stamping dies to form a sheet. The reconfigurability of the MPF machine is realised by a matrix of pins in the punches, each of which are controlled by a servo motor and are independently adjusted to an appropriate position to form different component geometry. The application of the MPF machine has been used for the manufacture of panels for high speed trains (Avant-Garde Communication), sheet metal forming (Sun et al 2007) and medical engineering applications (Chen et al 2006 and Tan et al 2007). The research undertaken into the MPF machine has included the minimization of spring back (Liu et al 2008), the digital manufacture of titanium prosphesis for cranioplasty (Chen et al 2006 and Tan et al 2006), the study of forming rules and characteristics of MPF for dish heads (Qian et al 2007), the finite element simulation of MPF sheet forming process (Cai and Liu 2005) and the surface design for a blank holder in the MPF (Sun et al 2007).

Reconfigurable Pin Tooling ${ }^{\mathrm{TM}}$ technology was developed by Surface Generation plc. using patented pin technology (Halford ${ }^{\mathrm{a}} 2005$, Halford $^{\mathrm{b}} 2005$ and Halford 2006). The pin tooling system developed by Surface Generation plc. has a matrix of square shaped pins made of a consumable tool material. When adjusting a pin, the pin rows next to the pin being adjusted can be separated automatically to allow individual pins, which are mounted on discretes, to be adjusted vertically by rotating them around the central axis. After adjustment, all the square pins are oriented at 45 degrees to allow for efficient packing with adjacent rows. Finally, the rough upper surface of adjusted pin ends is CNC machined to produce the final tool shape without the need for excessive material waste.

Although advanced research has been conducted with MPF technology, since every pin in the MPF system is individually controlled by a servo motor, the machine is very expensive, which prohibits the technology from being employed widely. Similar problems exist in the reconfigurable pin tooling technology developed by Surface Generation plc. 
The reconfigurable moulding machine, utilising discrete-pin tooling, can move pins automatically to desired positions by a CNC discrete driver, therefore, eliminating the need for employing servo motors to adjust individual pins, significantly reducing the cost of servo motors and the complexity of the machine system, and being more affordable for industry, e.g. SME companies. Having developed a vacuum forming machine shown in Figure 1, in which the pins are configured to a near-net shape and machined to final shape with minimal material removal, this paper discusses in detail the development of support software that enables an automatic adjustment of discrete-pins in order to represent different component geometry. This software enabling system has not been discussed within the remit of previous reconfigurable moulding systems.

Add here Figure 1: Frame of reconfigurable discrete pin tooling system

\section{Add here Figure 2: Screw-pin engagement}

\section{Methodology}

Identical standard discrete pins are used. There are two possible pin engagement methods as shown in Figure 2. Obviously, the gap between pins is smaller in Figure 2(a) than of that in Figure 2(b), thus the engagement method in Figure 2(a) is selected, leading to one less pin in the even row than those in the odd row. Assuming that the discrete-pin matrix is composed of $\mathrm{m} \times \mathrm{n}$ pins, let $\boldsymbol{P}_{i j}(\mathrm{x}, \mathrm{y}, \mathrm{z})$ denote the pin in row $i$ and column $j, \boldsymbol{P}_{i j}(\mathrm{x}, \mathrm{y}, \mathrm{z})$ is represented by the intersection point of the top surface and the central axis of the pin, then tooling space $\mathbf{S}_{\mathbf{t}}$ can be expressed as a set of these discrete points as:

$$
\boldsymbol{S}_{t}=\boldsymbol{P}_{11} \cup \ldots \cup \boldsymbol{P}_{i j \ldots} \cup \boldsymbol{P}_{m n}, \quad \mathrm{i} \in[1, \mathrm{~m}], \mathrm{j} \in[1, \mathrm{n}]
$$

The parameters of a discrete pin tooling include rows $\left(\boldsymbol{R}_{\boldsymbol{p}}\right)$ and columns $\left(\boldsymbol{C}_{\boldsymbol{p}}\right)$ of discrete pins $\left(\boldsymbol{C}_{p}\right.$ is the column number in the odd row), pin diameter $\left(\boldsymbol{D}_{\boldsymbol{p}}\right)$, length $\left(\boldsymbol{L}_{\boldsymbol{p}}\right)$ and pitch $\left(\boldsymbol{P}_{\boldsymbol{p}}\right)$. The distance between the two discrete-pin central axes in the $\mathrm{x}$ direction and in the $\mathrm{Y}$ direction, designated as $\boldsymbol{X}_{\boldsymbol{p}}$ and $\boldsymbol{Y}_{\boldsymbol{p}}$ as 
shown in Figure 2, is needed to identify the position of $\boldsymbol{P}_{i j}$, and is determined by the pin diameter $\left(\boldsymbol{D}_{\boldsymbol{p}}\right)$ and the Pitch $\left(\boldsymbol{P}_{\boldsymbol{p}}\right)$. When two identical external discretes are meshed together, the distance of the discrete pin in $\mathrm{X}$ direction $X_{p}$ is:

$$
\begin{aligned}
& \boldsymbol{X}_{p}=\boldsymbol{D}_{p}-0.649519 \times \boldsymbol{P}_{p} \\
& \boldsymbol{Y}_{p}=\frac{\sqrt{\mathbf{3}}}{\mathbf{2}} \times\left(\boldsymbol{D}_{p}-0.649519 \times \boldsymbol{P}_{p}\right)
\end{aligned}
$$

As shown in Figure 3, assuming that the coordinate frame of the discrete-pin matrix is in the centre of the matrix, the position of $\boldsymbol{P}_{\boldsymbol{i j}}$ is a function of $i$ and $j$. The function of the $\mathrm{Y}$ coordinate value of $\boldsymbol{P}_{\boldsymbol{i j}}$ is:

$$
\boldsymbol{P}_{i j} \cdot y=i \times \boldsymbol{Y}_{\boldsymbol{p}^{-}}\left(\boldsymbol{R}_{\boldsymbol{p}^{-}}-1\right) / 2 \times \boldsymbol{Y}_{\boldsymbol{p}}
$$

Since there is one pin less in even rows, the $x, y, z$ positions of the last pin in even row is assigned as zero. Otherwise, the function of the $x$ coordinate value of $\boldsymbol{P}_{i j}(x, y, z)$ is dependent on whether $i$ is odd or even:

$$
\begin{array}{ll}
\boldsymbol{P}_{i j .} X=j \times \boldsymbol{X}_{p^{-}}\left(\boldsymbol{C}_{p^{-1}}\right) / 2 \times \boldsymbol{X}_{\boldsymbol{p}} & \text { if in even row } \\
\boldsymbol{P}_{i j .} X=\mathrm{j} \times \boldsymbol{X}_{p^{-}}\left(\mathbf{C}_{p}-2\right) / 2 \times \boldsymbol{X}_{\boldsymbol{p}} & \text { if in odd row }
\end{array}
$$

Where $i \in\left[0, \boldsymbol{R}_{\mathrm{p}}-1\right]$ and $\mathrm{j} \in\left[1, \boldsymbol{C}_{p^{-}}-1\right]$

Add here Figure 3: Screw-pin position and its relation to the $\boldsymbol{R}_{p}$ and $\boldsymbol{C}_{\boldsymbol{p}}$

A general three dimensional component surface $S_{c}$ can be meshed as $\mathrm{m} \times \mathrm{n}$ NURBS patches,

$$
S_{c}=S^{11} \cup \ldots \cup S^{i j} \ldots \cup S^{m n}
$$

Where $\boldsymbol{S}^{i j}(x, y, z)$ denotes the $(i, j)^{\text {th }}$ NURBS patch of the $\boldsymbol{S}_{c}$ in response to the $\boldsymbol{P}_{i j}$

$$
\begin{aligned}
& P_{i j .} X-X_{p} / 2 \leq S^{i j} \cdot \mathrm{X} \leq P_{i j \cdot} \mathrm{X}+X_{p} / 2 \\
& P_{i j \cdot y} \cdot Y_{p} / 2 \leq S^{i j} . \mathrm{y} \leq P_{i j} \cdot \mathrm{y}+Y_{p} / 2
\end{aligned}
$$


Each of the patches can be discretised into many discreet points, and assuming that point cloud is well defined and can replace the surface model, $\boldsymbol{S}^{i j}$ can be further represented by $\boldsymbol{t}$ discreet nodes, then:

$$
S^{i j} \approx N_{1}^{i j} \cup \ldots \cup N_{k}^{i j} \ldots \cup N_{t}^{i j} \quad \mathrm{k} \in[1, t]
$$

Where $\mathbf{N}_{\mathbf{k}}^{\mathrm{ij}}(x, y, z)$ denotes the $\mathrm{k}^{\mathrm{th}}$ node within the patch $\mathbf{S}^{i j}$.

In order for the tooling space $\boldsymbol{S}_{\boldsymbol{t}}$ to represent the net-shape of the component geometry surface $\boldsymbol{S}_{c}$, whist having minimal material removed, then:

$$
\boldsymbol{P}_{i j \cdot} \cdot \mathbf{M}=\operatorname{Max}\left(\mathrm{N}_{1}^{\mathrm{ij}} \cdot z, \ldots, \mathbf{N}_{\mathrm{k}}^{\mathrm{ij}} \cdot z, \ldots, \mathrm{N}_{\mathrm{t}}^{\mathrm{ij}}, z\right)
$$

Let $\boldsymbol{P}_{i j}^{0}$ and $\boldsymbol{P}_{i j}^{1}$ be the $\boldsymbol{P}_{i j}$ for previous and current components respectively, then the amount of adjustment in degree $\boldsymbol{A}_{i j}$ for the $(i, j)^{\text {th }}$ discrete-pin is:

$$
\boldsymbol{A}_{i j}=\left(\boldsymbol{P}_{i j}^{1} \cdot z-\boldsymbol{P}_{i j}^{0} \cdot z\right) / \boldsymbol{P}_{p} \times 360
$$

\section{Software implementation}

\section{Add here Figure 4: Software framework}

Discrete-pin tooling control is conducted in three steps and the detail of the framework is shown Figure 4. Different software platforms including CAD/CAM (Unigraphics), Finite Element Analysis software (ABAQUS) andscanning software (Gom) are integrated into the interface and developed using Visual Basic. The system is composed of three parts: (1) Component discretization, (2) Discrete-pin construction, adjustment, evaluation and $\mathrm{G}$ code generation (SCAG) and (3) Display and verification.

\subsection{Component discretization}

In order to obtain the component position information in response to the discrete-pin matrix, it is essential to discretize the 3D component surfaces. There are two types of discretization: discretization of 3D CAD model and 
discretization of the 3D physical model. The discretization of 3D CAD model is also called mesh generation, and is the same as that of Finite Element Analysis, and is therefore conducted using FEA software (ABAQUS/CAE). Discretization of a 3D physical model, employed when CAD models are not available, is conducted through scanning by using the Gom scanner.

To avoid meshing the component surface with the finite element analysis environment, it is important to obtain a good quality of nodes that are evenly distributed over the component surface. Also, when transferring geometry from a CAD environment to an FEA environment, information loss occurs frequently due to the disparity between the interpretation and data expression of different software, therefore it is first important to repair the geometry before the discretization takes place. The detailed steps for the geometry discretization are shown in Figure 5.

Add here Figure 5: Mesh generation within Finite Element Analysis software

\subsection{Discrete-pin construction, adjustment, evaluation and G code generation (SCAG)}

SCAG is a user friendly interface developed within a visual basic environment. The purpose of the system is to allow users to process an output file from the previous discretization process in order to obtain point position and thus make a decision on whether a new discrete-pin matrix or the previous discrete-pin matrix should be used. If a new discrete-pin matrix is needed, it can be constructed parametrically, otherwise, the previous discrete-pin matrix can be retrieved. After this process has taken place, the amount of discrete-pin adjustment is calculated based on the height difference between the discretepin matrix and the geometry of the component; and an assessment is made on whether the discrete-pin matrix is suitable for the component. If the conclusion is yes, then a G code for the Fagor CNC controller is generated automatically, otherwise, it will feedback to the user so that the user can modify the discrete-pin matrix to avoid problems occurring at a later downstream stage. In summary, the SCAG is composed of five parts: 
1) Point processing: to process the FEA and scanned component $s$ to obtain the point (node) coordinate position;

2) Parametric discrete-pin matrix construction: allows the user to retrieve the previous discrete-pin matrix or construct a new discrete-pin matrix;

3) Discrete-pin adjustment: calculate the amount of adjustment for each discrete-pin;

4) Saving and retrieving a discrete-pin matrix;

5) Evaluation: to assess whether or not the overall size of a discrete-pin matrix and the remaining length of individual pins are sufficient for a new component.

6) G code generation: Automatic generation of a G-code for the discrete pin adjustment for the Fagor controllers.

Figure 6 shows the interface which facilitates the user to 1) choose to create a new discrete-pin matrix or retrieve a previously generated discrete-pin matrix, 2) Select the component geometry file as that either generated from Abaqus software or from the file generated from a scanner; 3) If the discrete-pin matrix is retrieved rather than constructed from new, the user needs to select the previous component file for the retrieved discrete-matrix.

Add here Figure 6: Interface for discrete pin construction, adjustment and G code generation

\subsection{Discrete-pin matrix display and verification}

After calculation of the adjustment required for the discrete-pins and the generation of a G code, it may be necessary to display the discrete-pin within in a CAD/CAM environment to verify whether or not the discrete-pins are in the correct position before any physical machining is conducted. This prevents any collision or failure in the machine execution stage.

The geometry and the final position of the discrete-pins are generated automatically, based on the discrete-pin matrix file by a programme 
developed within the Unigraphics/GRIP environment. Each discrete pin is simplified to a cylinder in the GRIP program. "Do Loop segments" is used to generate every discrete pin in the tooling.

\section{Case study}

As shown in Figure 7, a car model can be generated within commercial software and saved as a neutral file format (*igs). as shown in Figure 7(a). The car model was inputted into ABAQUS CAD to be discretized as shown in Figure $7(\mathrm{~b})$. The meshed file was exported to the interface shown in Figure 6 to calculate the amount of discrete-pin adjustment. The final position of the discrete-pin was saved as a txt file and was exported to Unigraphics using the GRIP programme. The 3D simplified pins matrix were created automatically and compared with the original CAD model. Once the position of the discretepins has been verified, the pin matrix file will be used as input for the physical pin adjustment by using an automated screw driver and step motors as shown in Figure $7(\mathrm{~d})$. As the model is relatively complicated, to achieve a smooth surface in resulting moulded components, the pins need to be subsequently machined as shown in Figure 7(e). A vacuum formed product using the pin mould can be found in Figure $7(f)$.

Add Figure Figure 7: Case study

\section{Conclusions}

Reconfigurable pin moulding is in much demand in order to make the moulding industry more responsive to unpredictable market change. Having developed a CNC machine utilising discrete-pin tooling for reconfigurable vacuum forming, this paper has detailed the development of support software that enables an automated adjustment of discrete-pins for the moulding of components by having different geometry. The software is composed of three parts: a) component discretization using Finite element software or scanning; b) SCAG is developed based on Visual basic to process the discretization 
files, construct discrete-pins, calculate the amount of adjustment needed for each individual discrete-pin and generation of a $G$ code, c) display and verification using commercial CAD/CAM software. The vacuum forming of a car model has been used as a case study.

\section{References}

Avant-Garde Communication LTD, Online international aviation news magazine, $\quad$ http://www.skycontrol.net/industry/dataform-flexible-andreconfigurable-tooling-for-manufacturing-aircraft-panels/ , last logged on 5th April 2009

Cai Z. Y., Liu M-Z., 2005, Finite Element simulation of multi-point sheet forming process based on implicit scheme, Journal of material processing technology, 161, 449-455

Camp E. C. 1978, Grinding machine, United States Patent, Patent No. 4068412

Chen J. J., Liu W., Li M-Z, Wang C-T, 2006, Digital manufacture of titanium prosthesis for cranioplasty, International journal of advanced manufacturing technology, 27, 1148-1152

Fleming W., 1987, Vertical Three-Dimensional Image Screen, U.S. Patent, Patent No. 4,654,989, issued April 7

Halford, B. ${ }^{a}, 2005$, World Intellectual property organisation, Improved tooling system, patent filed by Surface generation plc, Patent number: WO2005/061183 A2

Halford B. ${ }^{\mathrm{b}}, 2005$ World Intellectual property organisation, Workpiece support, patent filed by Surface generation plc, Patent number: WO2005/061182 A2

Halford B., 2006, World Intellectual property organisation, Tooling system with array of longitudinally movable elements, patent filed by Surface generation plc, Patent number: WO2006/00817 A1

KOSTYRKA GmbH, Universal holding fixture, http://www.kostyrka.com/en/products/universal-holding-fixture.html, last logged in on 15th April 2009

Liu C-Q, Li M-Z, Fu W-Z, 2008, Principles and apparatus of multi-point forming for sheet metal, International Journal of Advanced Manufacturing Technology, 35(11-12), 1227-1233

MATRIX GmbH Stuttgart, http://www.matrix-innovations.com/

Meintrup H. W. ,1998, Work Holding Device, U.S. Patent, Patent, No. 5988618

Munro C., Walczyk D., 2007, Reconfigurable pin-type tooling: A survey of prior art and reduction to practice, Journal of Manufacturing Science and Engineering, Transactions of the ASME, 129 (3), 551-565 
Qian Z. R., Li M-Z., Tan F. X. 2007, The analysis on the process of multi-point forming to dish head, journal of material processing technology, 187-188, 471475

Rong Y., Tao R., Tang X., 2000, Flexible fixturing with phase-change materials. Part 1. Experimental study on magnetorheological fluids, International Journal of Advanced Manufacturing Technology, 16(11), 822829

Surface generation plc, http://www.surface-generation.com/

Sun G., Li M. Z., Yan X. P., Zhong P. P.,2007, Study of blank holder technology on multi-point forming of thin sheet metal, Journal of materials processing technology, 187-188, 517-520

Tan F. X., Li M-Z, Lai Z. Y., 2007, "Research on the process of multi-point forming for the customised titanium alloy cranial prosthesis", Journal of materials processing technology, 187-188, 453-457 


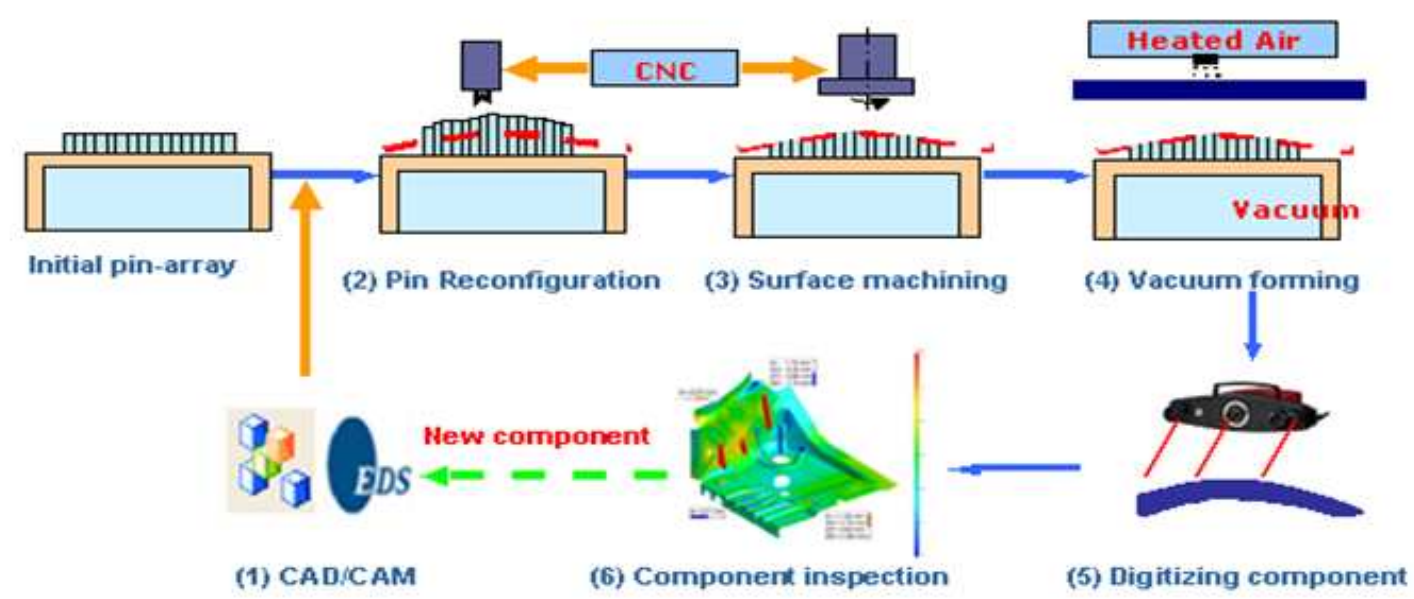

Figure 1: Frame of reconfigurable screw pin tooling system

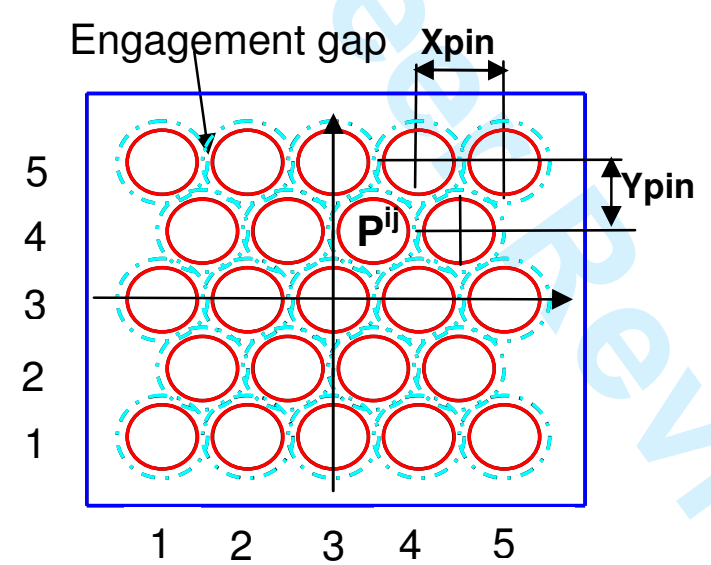

(a) Triangular pattern

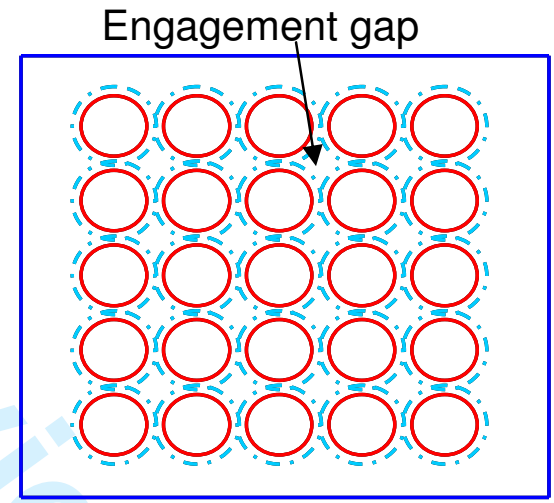

(b) Rectangular pattern

Figure 2: Screw-pin engagement methods 


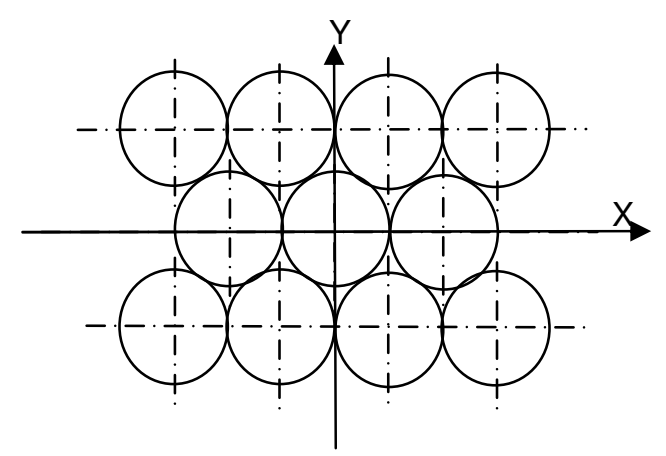

(a) $\mathbf{R}_{\mathbf{p}}$ : odd, $\mathbf{C}_{\mathbf{p}}=$ even

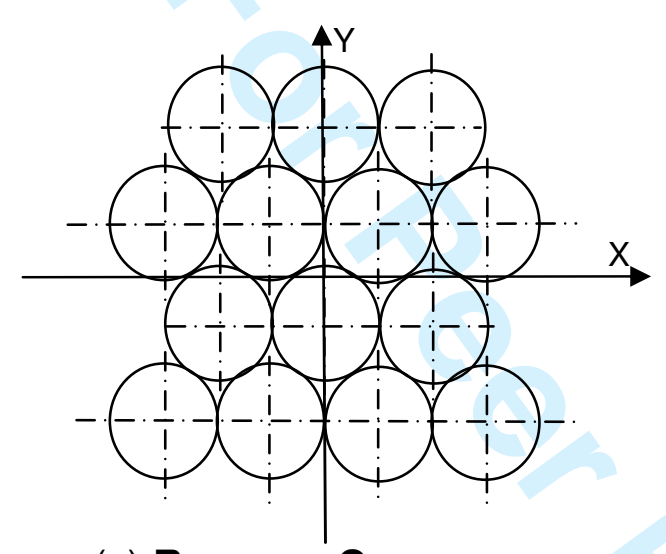

(c) $\mathbf{R}_{\mathbf{p}}$ : even, $\mathbf{C}_{\mathbf{p}}$ : even

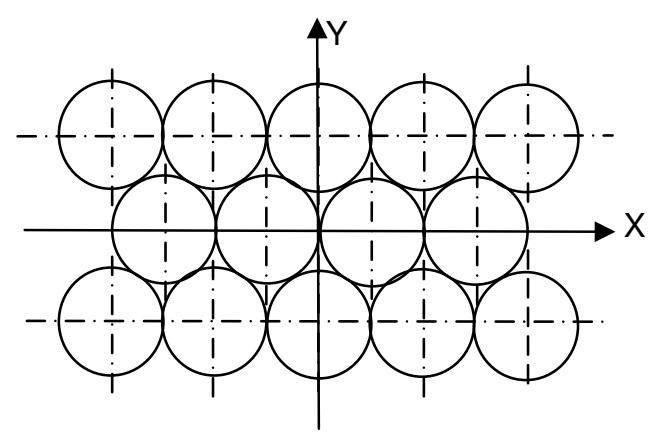

(b) $\mathbf{R}_{\mathbf{p}}$ : odd, $\mathbf{C}_{\mathbf{p}}$ : odd

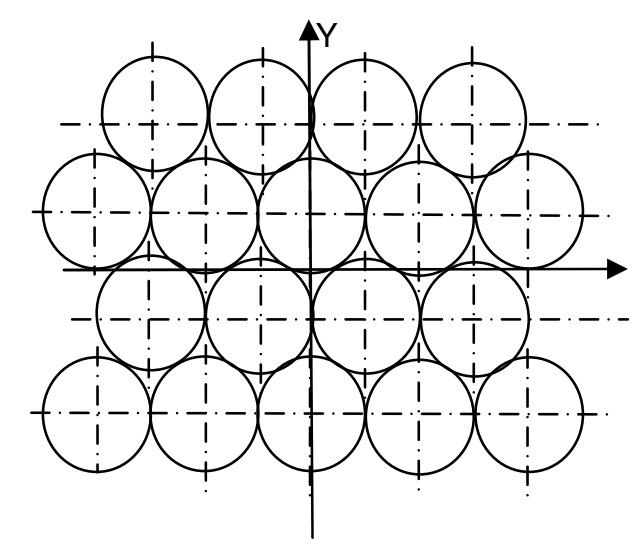

(d) $\mathbf{R}_{\mathbf{p}}$ : even, $\mathbf{C}_{\mathbf{p}}$ : odd

Figure 3: Screw-pin position and its relation to the $\mathbf{R}_{p}$ and $\mathbf{C}_{p}$ 


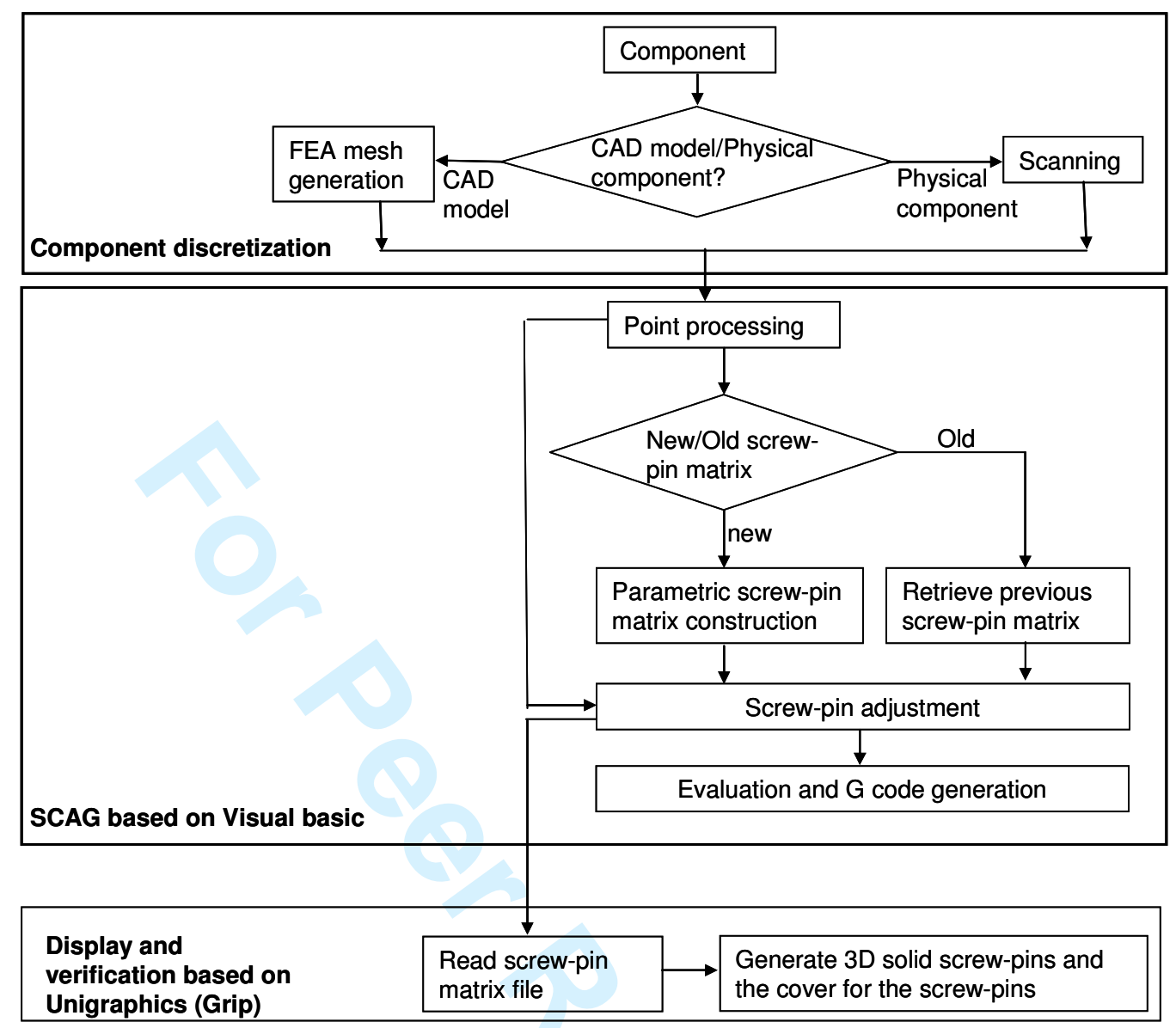

SCAG: Screw-pin construction, adjustment, evaluation and G code generation

Figure 4: Software framework 


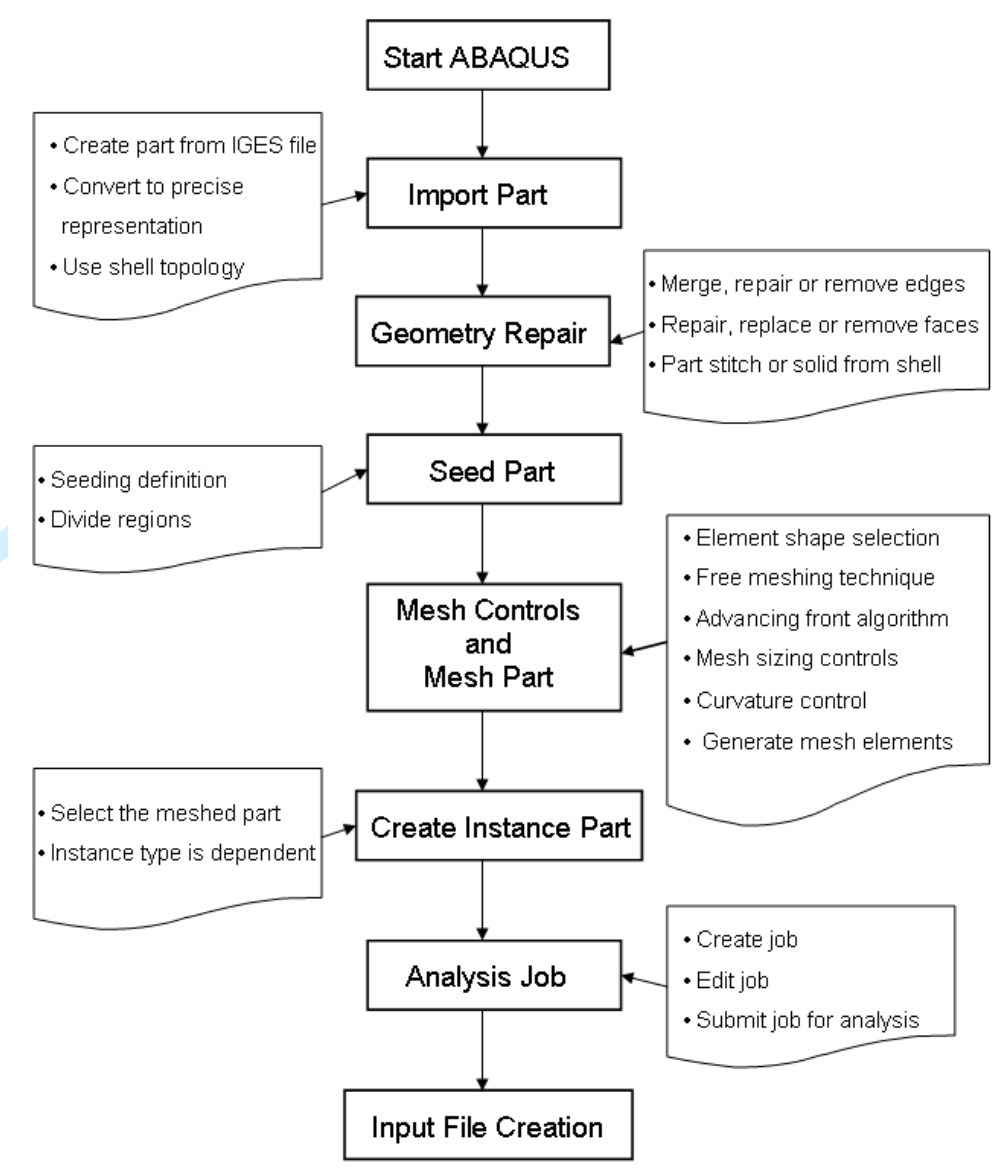

Figure 5: Mesh generation within Finite Element Analysis software 


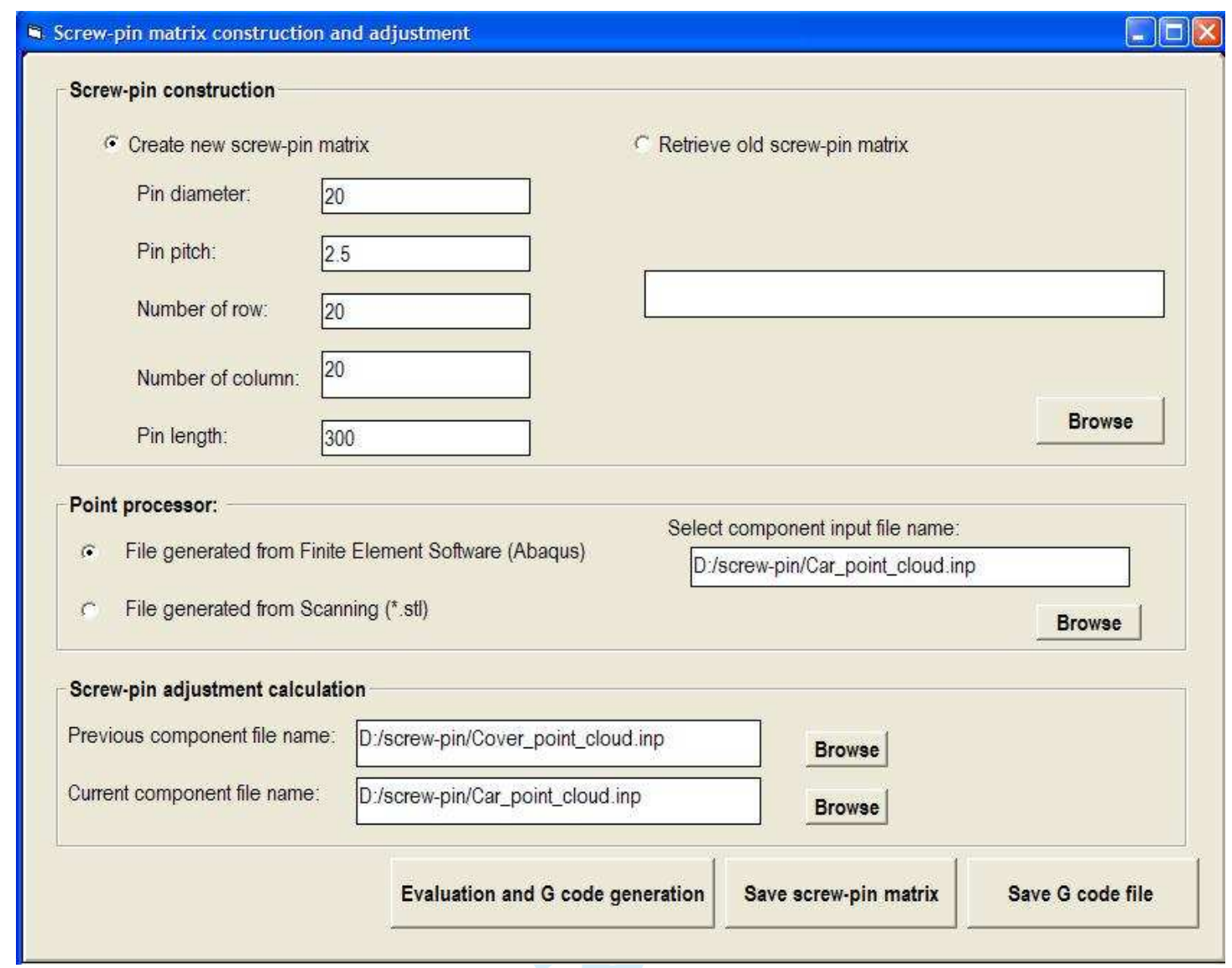

Figure 6: Interface for screw pin construction, adjustment and G code generation 


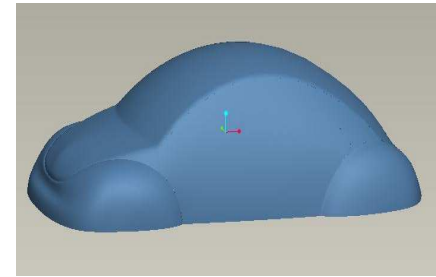

(a) CAD model

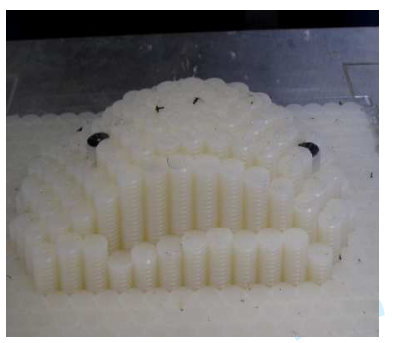

(d) G code generation and screw-pin adjusted physically

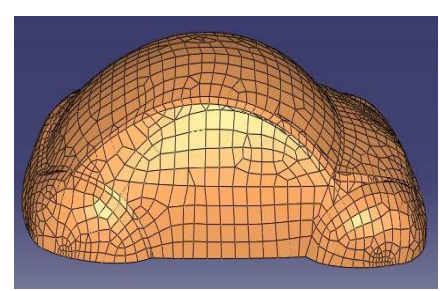

(b) Component discretised

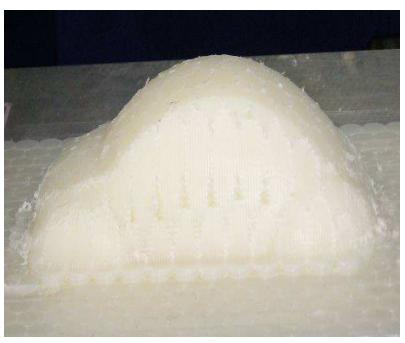

(e) Screw-pin machined

Figure 7: Case study

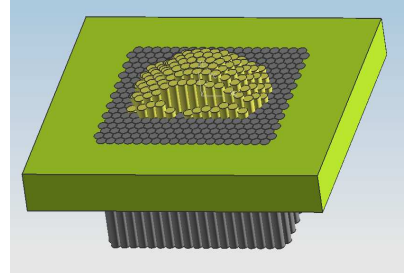

(c) Screw-pin adjusted within Unigraphics

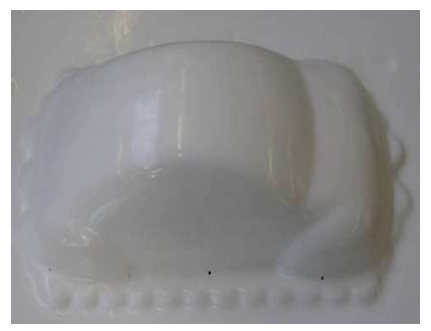

(f) Vacuum formed component 